\title{
X-ray structure and activity analysis of 3-bromomethyl -2-chloro-quinoline
}

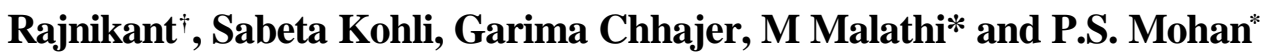 \\ ${ }^{\dagger}$ Chemical Crystallography Laboratory, Post-Graduate Department of Physics, University of Jammu, Jammu Tawi - 180 006, INDIA \\ * Department of Chemistry, Bharathiar University, Coimbatore (Tamil Nadu), INDIA \\ Corresponding author. E-mail: rk_paper@rediffmail.com
}

\begin{abstract}
The structure of 3-bromomethyl-2-chloro-quinoline crystallizes in the triclinic crystal space group $P^{\prime} 1$ with unit cell parameters $a=6.587(2), b=7.278(3), c=10.442(3) \AA, a=83.59(3)^{\circ}, b=75.42(2)^{\circ}, g=77.39(3)^{\circ}, Z=2, V=$ 471.9(3) $\AA^{3}$. The structure has converged to a final R-value of 0.0734 . The phenyl Ring-B has normal geometry while the pyridine Ring-A has slightly distorted conformation. The asymmetry parameter calculations, i.e., $\mathrm{DC}_{2}$ and $\mathrm{DC}_{\mathrm{s}}$ for the pyridine ring indicates that the structure is planar. There exists one intramolecular hydrogen bonded interaction of the type $\mathrm{C}-\mathrm{H} \ldots \mathrm{Cl}$ and one $\mathrm{C}-\mathrm{H} \ldots \mathrm{N}$ intermolecular interaction. The structure is stabilized by Van der Waals forces.

Keywords: Crystal structure, Activity, Quinoline, Hetereocyclic compounds, X-ray structure
\end{abstract}

\section{INTRODUCTION}

Quinoline is a heterocyclic aromatic organic compound characterized by a two- ring structure in which the benzene ring is fused to pyridine moiety. Quinolines and their derivatives are important scaffolds because of their wide spectrum of biological activities (Saito et al., 2001; Lekhok et al., 2008). They are used as efficient drugs for the treatment of malaria (Robert et al, 1998; Palani et al, 2004) and possess antibacterial, antiarrhythmic, antihypertensive and antibiotic properties as well. Quinoline alkaloids also act as immuno-suppressant inhibitors and virucides (Gilchrist et al., 1997; Kouznetsov et al., 1998; Garcia et al., 2000).

\section{MATERIALS AND METHODS}

The title compound is a heterocyclic quinoline derivative which has been synthesized by conventional chemical procedures. The chemical structure, as shown in Fig. 1, has been established on the basis of IR, UV, NMR and mass spectral data. The experimental procedure adopted for activity and X-ray structure analysis is presented in the following sections.

(i) Activity Determination: The activity of the molecule has been determined by making use of PASS software (Poroikov et al., 2005). The input for activity determination is the molecular fragment which undergoes computation against a large number of known / reported activities. The information which can be deduced from the computational process is the probability of a given molecule to be "active" or "inactive" on a scale of 0 to 1 . The probabilities are generally referred to as $\mathrm{P}_{\mathrm{a}}$ and $\mathrm{P}_{\mathrm{i}}$. These values provide us a way to suggest possible drug likeness for a given molecule on the basis of a comparative analysis of the activity data. This helps us to have a relationship between the structure and its activity. From the activity analysis, it has been found that the title compound has 23 substructure descriptors, and exhibits five possible activities at $\mathrm{P}_{\mathrm{a}}>\mathrm{P}_{\mathrm{i}}$. The probability of drug likeness for the investigated molecule is 0.056. The details of the activities are presented in Table 1.

(ii) X-ray Crystallography: A single crystal having a well-defined morphology was selected for threedimensional crystal intensity data collection on a computer-controlled single crystal X-ray diffractometer (X'calibur system-Oxford diffraction-make, U.K) by using MoK $\alpha$ radiation $(?=0.71073 \AA)$. The data were collected by using CrysAlis ${ }^{\text {Pro }}$ (2007) software. A total number of 4003 reflections were recorded of which 2529 reflections were found unique having index range: $-9 \leq \mathrm{h}$ $\leq 9,-10 \leq \mathrm{k} \leq 9,-14 \leq 1 \leq 14)$. The data were reduced by using CrysAlisRED (2007).

The structure has been obtained by employing direct methods using SHELXS86 software (Sheldrick, 1986). All non- hydrogen atoms of the molecule were located from the E-map (electron density map). Refinement has been carried out by full-matrix least-squares method on $\mathrm{F}^{2} \mathrm{using}$ SHELXL97 software (Sheldrick, 1997). The anistropic refinements with thermal parameters for non-hydrogen atoms and subsequent refinement cycles converged the $\mathrm{R}$-factor to 0.0734 . The maximum and minimum residual electron density is 1.027 and -0.994 e. $\AA^{-3}$, respectively. The crystallographic data are listed in Table 2. 
Table 1. Details of the activities.

\begin{tabular}{|c|c|c|}
\hline $\begin{array}{c}P_{a} \text { (Probability } \\
\text { of the } \\
\text { molecule to be } \\
\text { active) }\end{array}$ & $\begin{array}{c}P_{i} \text { (Probability } \\
\text { of the } \\
\text { molecule to be } \\
\text { inactive) }\end{array}$ & Possible Activities \\
\hline 0.080 & 0.030 & Saluretic \\
\hline 0.097 & 0.047 & $\begin{array}{c}\text { Phosphodiesterase IV } \\
\text { inhibitor }\end{array}$ \\
\hline 0.037 & 0.008 & Angiotensin antagonist \\
\hline 0.035 & 0.008 & $\begin{array}{c}\text { Angiotensin II receptor } \\
\text { antagonist }\end{array}$ \\
\hline 0.029 & 0.013 & $\begin{array}{c}\text { Angiotensin AT1 receptor } \\
\text { antagonist }\end{array}$ \\
\hline
\end{tabular}

Table 2: Crystal data and structure refinement details.

\begin{tabular}{ll}
\hline Molecular formula & $\mathrm{C}_{10} \mathrm{H}_{7} \mathrm{Br} \mathrm{Cl} \mathrm{N}$ \\
Formula weight & 256.53 \\
Temperature & $293(2) \mathrm{K}$ \\
Wavelength (MoKa) & $0.71073 \AA$ \\
Crystal system, space group & Triclinic, $\mathrm{P} \overline{1}$ \\
Unit cell dimensions & $\mathrm{a}=6.587(2) \AA, \alpha=83.59(3)^{\circ}$ \\
& $\mathrm{b}=7.278(3) \AA, \quad \beta=75.42(2)^{\circ}$ \\
& $\mathrm{c}=10.442(3) \AA, \gamma=77.39(3)^{\circ}$ \\
Volume & $471.9(3) \AA^{3}$ \\
No. of molecules per unit cell(Z) & 2 \\
Calculated density & $1.805 \mathrm{Mg} / \mathrm{m}^{3}$ \\
Absorption coefficient & $4.584 \mathrm{~mm}{ }^{-1}$ \\
F(000) & 252 \\
Crystal size & $0.30 \times 0.25 \mathrm{x} 0.20 \mathrm{~mm}$ \\
Theta range for data collection & 3.26 to $30.25^{\circ}$ \\
Limiting indices & $-9 \leq \mathrm{h} \leq 9,-10 \leq \mathrm{k} \leq 9,-14 \leq 1 \leq 14$ \\
Reflections collected / unique & $4003 / 2529[\mathrm{R}(\mathrm{int})=0.0415]$ \\
Refinement method & Full-matrix least-squares on $\mathrm{F}^{2}$ \\
Data/restraints/parameters & $2529 / 0 / 143$ \\
Goodness-of-fit on $\mathrm{F}^{2}$ & 1.094 \\
Final R indices [I $>2 \sigma(\mathrm{I})]$ & $\mathrm{R} 1=0.0734, \mathrm{wR} 2=0.1851$ \\
R indices (all data) & $\mathrm{R} 1=0.0917, \mathrm{wR} 2=0.2013$ \\
Extinction coefficient & $0.003(5)$ \\
Largest diff. peak and hole & 1.027 and $-0.994 \mathrm{e} . \AA^{-3}$ \\
\hline &
\end{tabular}

\section{RESULTS AND DISCUSSION}

The final atomic coordinates and equivalent isotropic thermal factors for all the non-hydrogen atoms are listed in Table 3. Bond distances and bond angles for nonhydrogen atoms are listed in Table 4 . Torsion angles for non-hydrogen atoms are listed in Table 5. An ORTEP view of the molecule indicating atomic numbering scheme (thermal ellipsoids drawn at 50\% probability level), is shown in Fig. 2 (Farrugia, 1997). The geometrical calculations have been performed using PARST program (Nardelli, 1995).

The molecule consists of two six-membered rings which are labeled as Ring-A and B, respectively. Ring- A is chloroquinoline moiety while the Ring- B is the phenyl (benzene) ring. In Ring-A, the bond distances show significant deviation from the standard $\mathrm{C}-\mathrm{C}$ and $\mathrm{C}-\mathrm{N}$<smiles>Clc1nc2ccccc2cc1CBr</smiles>

Fig. 1. Chemical structure of 3-bromomethyl-2-chloroquinoline.

distances. The $\mathrm{C} 1=\mathrm{N} 1$ and N1-C5 distances of 1.283(7) and $1.350(7) \AA$ are deviated significantly from the standard distances. The carbon-chlorine $[\mathrm{C} 1-\mathrm{Cl}]$ distance of 1.734 (6) $\AA$ is comparable with the values as obtained in an analogous structure of 2-chloro-3-( $\beta$ nitrovinyl)quinoline (Palani et al., 2004). The Br-C10 distance of 1.956(6) $\AA$ is quite close to the standard value of $1.94 \AA$ (Schneider et al., 2008). The C4-C5 bond acts as a fusion bond between Ring-A and Ring- B which are loaded symmetrically.

The endocyclic bond angle C1-N1-C5 [118.0(5) $\left.{ }^{\circ}\right]$ is slightly inconsistent with the corresponding values obtained for some analogous structures (Sudha et al., 1995a; 1995b; Sudha et al., 1997; Rajnikant et al., 2002). The shortening of this angle could be attributed to the stretching which the carbon-chlorine [C1-Cl] bond might have created in Ring-A. The endocyclic bond angle $\mathrm{C} 1-$ $\mathrm{C} 2-\mathrm{C} 3\left[115.7(5)^{\circ}\right]$ is also short as compared to its usual value of $120^{\circ}$. This could also be due to the location of $\mathrm{CH}_{2} \mathrm{Br}$ group at $\mathrm{C} 2$ position of the quinoline ring. The phenyl Ring- B has a very normal geometry in terms of its bond distances and angles.

The dihedral angle between plane $1[\mathrm{C} 1, \mathrm{C} 2, \mathrm{C} 3, \mathrm{C} 4, \mathrm{C} 5$ and N1] and plane 2 [C4, C5, C6, C7, C8 and C9] of the molecule is $179.07(1)^{\circ}$. This, more or less, is equal to $180^{\circ}$ $\left(\right.$ or $0^{\circ}$ ) which means that the molecule is strictly planar and the individual rings do not exhibit any torsion along C4-C5 bond. The magnitude of torsion along C2-C10 [i.e.,

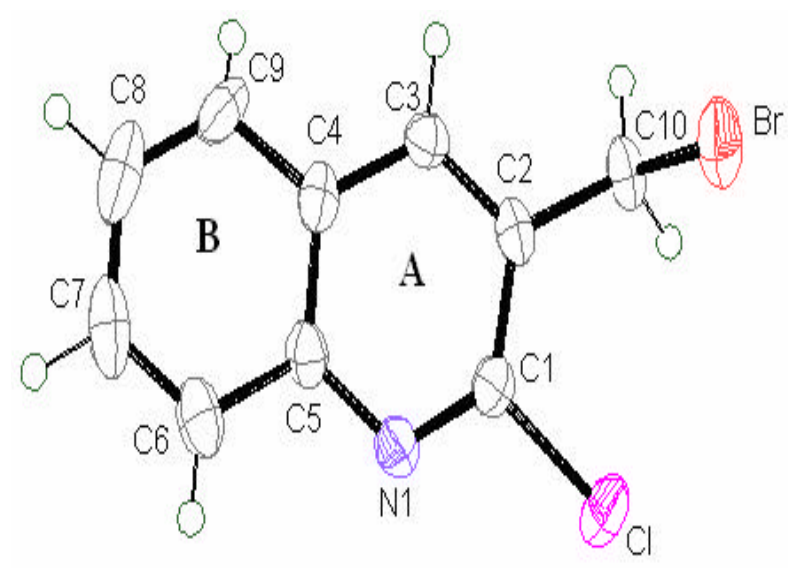

Fig. 2. ORTEP view of the full molecule (thermal ellipsoids drawn at $50 \%$ probability level). 
Table 3. Atomic coordinates and equivalent isotropic temperature factors $(\AA)$ with e.s.d's in parentheses, for non-hydrogen atoms.

\begin{tabular}{lcccc}
\hline Atom & $\mathbf{x}$ & $\mathbf{y}$ & $\mathbf{z}$ & $\mathbf{U}(\mathbf{e q})^{*}$ \\
\hline $\mathrm{Br}$ & $0.2152(1)$ & $0.2044(1)$ & $0.4938(1)$ & $0.0053(1)$ \\
$\mathrm{Cl}$ & $0.7571(3)$ & $0.2843(3)$ & $0.3359(2)$ & $0.0054(1)$ \\
$\mathrm{N}(1)$ & $0.7547(7)$ & $0.2218(7)$ & $0.0995(5)$ & $0.0032(1)$ \\
$\mathrm{C}(1)$ & $0.6311(9)$ & $0.2798(8)$ & $0.2095(5)$ & $0.0031(1)$ \\
$\mathrm{C}(3)$ & $0.3172(9)$ & $0.3340(7)$ & $0.1348(5)$ & $0.0030(1)$ \\
$\mathrm{C}(2)$ & $0.4070(9)$ & $0.3408(7)$ & $0.2356(5)$ & $0.0029(1)$ \\
$\mathrm{C}(4)$ & $0.4431(9)$ & $0.2694(7)$ & $0.0117(5)$ & $0.0031(1)$ \\
$\mathrm{C}(10)$ & $0.2775(11)$ & $0.4119(9)$ & $0.3638(6)$ & $0.0037(1)$ \\
$\mathrm{C}(9)$ & $0.3632(13)$ & $0.2565(10)$ & $-0.0970(7)$ & $0.0043(1)$ \\
$\mathrm{C}(5)$ & $0.6648(9)$ & $0.2138(7)$ & $-0.0019(5)$ & $0.0030(1)$ \\
$\mathrm{C}(7)$ & $0.7089(14)$ & $0.1355(10)$ & $-0.2224(7)$ & $0.0051(2)$ \\
$\mathrm{C}(6)$ & $0.7954(11)$ & $0.1460(8)$ & $-0.1212(6)$ & $0.0041(1)$ \\
$\mathrm{C}(8)$ & $0.4916(15)$ & $0.1921(10)$ & $-0.2108(7)$ & $0.0055(2)$
\end{tabular}

$\mathrm{U}_{\mathrm{eq}}{ }^{*}=(\mathbf{1 / 3}){ }_{\mathrm{i}}, \mathrm{j}_{\mathrm{j}} \mathrm{U}_{\mathrm{ij}} \mathrm{a}_{\mathrm{i}} \mathrm{a}_{\mathrm{j}}{ }^{*}\left(\mathbf{a}_{\mathrm{i}} \mathbf{a}_{\mathrm{j}}\right)$

Table 4. Bond distances $(\AA)$ and angles $\left(^{\circ}\right)$ with e.s.d's in parentheses for non-hydrogen atoms.

\begin{tabular}{|c|c|c|c|}
\hline Bond Lengths (̊̊) & & & \\
\hline $\mathrm{Br}-\mathrm{C}(10)$ & $1.956(6)$ & $C(2)-C(10)$ & $1.475(7)$ \\
\hline $\mathrm{Cl}-\mathrm{C}(1)$ & $1.734(6)$ & $\mathrm{C}(4)-\mathrm{C}(9)$ & $1.387(8)$ \\
\hline $\mathrm{N}(1)-\mathrm{C}(1)$ & $1.283(7)$ & $\mathrm{C}(4)-\mathrm{C}(5)$ & $1.402(8)$ \\
\hline $\mathrm{N}(1)-\mathrm{C}(5)$ & $1.350(7)$ & $\mathrm{C}(9)-\mathrm{C}(8)$ & $1.339(11)$ \\
\hline $\mathrm{C}(1)-\mathrm{C}(2)$ & $1.410(8)$ & $C(5)-C(6)$ & $1.395(8)$ \\
\hline$C(3)-C(2)$ & $1.341(8)$ & $C(7)-C(6)$ & $1.338(10)$ \\
\hline $\mathrm{C}(3)-\mathrm{C}(4)$ & $1.410(8)$ & $C(7)-C(8)$ & $1.378(12)$ \\
\hline \multicolumn{4}{|l|}{ Bond Angles $\left({ }^{\circ}\right)$} \\
\hline $\mathrm{C}(1)-\mathrm{N}(1)-\mathrm{C}(5)$ & $118.0(5)$ & $\mathrm{C}(5)-\mathrm{C}(4)-\mathrm{C}(3)$ & 117.9(5) \\
\hline $\mathrm{N}(1)-\mathrm{C}(1)-\mathrm{C}(2)$ & $126.4(5)$ & $\mathrm{C}(2)-\mathrm{C}(10)-\mathrm{Br}$ & 111.2(4) \\
\hline $\mathrm{N}(1)-\mathrm{C}(1)-\mathrm{Cl}$ & $115.5(4)$ & $\mathrm{C}(8)-\mathrm{C}(9)-\mathrm{C}(4)$ & 121.6(7) \\
\hline $\mathrm{C}(2)-\mathrm{C}(1)-\mathrm{Cl}$ & $118.0(4)$ & $\mathrm{N}(1)-\mathrm{C}(5)-\mathrm{C}(6)$ & 119.0(5) \\
\hline $\mathrm{C}(2)-\mathrm{C}(3)-\mathrm{C}(4)$ & $120.9(5)$ & $\mathrm{N}(1)-\mathrm{C}(5)-\mathrm{C}(4)$ & $121.0(5)$ \\
\hline $\mathrm{C}(3)-\mathrm{C}(2)-\mathrm{C}(1)$ & $115.7(5)$ & $\mathrm{C}(6)-\mathrm{C}(5)-\mathrm{C}(4)$ & $119.9(6)$ \\
\hline $\mathrm{C}(3)-\mathrm{C}(2)-\mathrm{C}(10)$ & $121.4(5)$ & $\mathrm{C}(6)-\mathrm{C}(7)-\mathrm{C}(8)$ & $120.8(6)$ \\
\hline$C(1)-C(2)-C(10)$ & $122.9(5)$ & $C(7)-C(6)-C(5)$ & $119.9(7)$ \\
\hline $\mathrm{C}(9)-\mathrm{C}(4)-\mathrm{C}(5)$ & $117.5(6)$ & $C(9)-C(8)-C(7)$ & $120.4(7)$ \\
\hline $\mathrm{C}(9)-\mathrm{C}(4)-\mathrm{C}(3)$ & $124.6(6)$ & & \\
\hline
\end{tabular}

$\mathrm{C} 1-\mathrm{C} 2-\mathrm{C} 10-\mathrm{Br}=-82.03^{\circ}$ and $\left.\mathrm{C} 3-\mathrm{C} 2-\mathrm{C} 10-\mathrm{Br}=99.39^{\circ}\right]$ is quite obvious as the $-\mathrm{CH}_{2} \mathrm{Br}$ group has free rotation of the quinoline moiety at $\mathrm{C} 2$ position. In order to ensure about the planarity of Ring-A, the asymmetry parameters $\Delta \mathrm{C}_{2}$ and $\Delta \mathrm{C}_{\mathrm{s}}$ were calculated by using CONFOR software (Chand, 2008). The values for $\Delta \mathrm{C}_{2}$ and $\Delta \mathrm{C}_{\mathrm{s}}$ are 0.109773 and 0.53507 , respectively. These calculations reveal the planar character of the pyridine ring. These parameters are based on the work of Duax and Norton (1975).

The molecules in the unit cell as packed along the a-axis (Fig. 3) are placed in reversed orientations. Since all the hydrogen atoms were located from the difference map, their role in understanding molecular interactions becomes all the more important. The bromine atoms are found to be located strategically in such a way that when joined through a line, they appear to be forming a onedimensional array passing through the centre of the unit cell. There exists two hydrogen bonded interactions. The $\mathrm{C} 10-\mathrm{H} 10 \ldots \mathrm{Cl}$ intramolecular hydrogen bond gives rise to a virtual five membered ring; thus making the present molecule look like a three ring structure. The C6-H6...N1 intermolecular hydrogen bond makes an extended network amongst the stacked layers and this bonding helps the molecules to acquire stability in the unit cell. 
Table 5. Torsion angles $\left({ }^{\circ}\right)$ with e.s.d's given in parentheses, for non-hydrogen atoms.

\begin{tabular}{llll}
\hline C5-N1-C1-Cl & $179.39(2)$ & C3-C2-C10-Br & $99.39(3)$ \\
C5-N1-C1-C2 & $-1.31(5)$ & C3-C4-C9-C8 & $-179.38(3)$ \\
C1-N1-C5-C4 & $0.78(4)$ & C5-C4-C9-C8 & $0.47(4)$ \\
C1-N1-C5-C6 & $-178.17(3)$ & C3-C4-C5-N1 & $0.02(4)$ \\
Cl-C1-C2-C3 & $-179.79(2)$ & C3-C4-C5-C6 & $178.97(3)$ \\
C1-C1-C2-C10 & $1.55(4)$ & C9-C4-C5-N1 & $-179.84(3)$ \\
N1-C1-C2-C3 & $0.93(5)$ & C9-C4-C5-C6 & $-0.89(4)$ \\
N1-C1-C2-C10 & $-177.74(3)$ & C4-C9-C8-C7 & $0.40(5)$ \\
C4-C3-C2-C1 & $-0.02(4)$ & N1-C5-C6-C7 & $179.42(3)$ \\
C4-C3-C2-C10 & $178.67(3)$ & C4-C5-C6-C7 & $0.45(4)$ \\
C2-C3-C4-C9 & $179.45(3)$ & C8-C7-C6-C5 & $0.43(4)$ \\
C2-C3-C4-C5 & $-0.39(4)$ & C6-C7-C8-C9 & $-0.87(5)$ \\
C1-C2-C10-Br & $-82.02(3)$ & & \\
\hline
\end{tabular}

Table 6. Geometry of intermolecular and intramolecular hydrogen bond interactions (e.s.d's in parentheses).

\begin{tabular}{|c|c|c|c|c|}
\hline$[\mathbf{X}-\mathbf{H} . . . A]$ & $\mathrm{D}[\mathrm{X}-\mathrm{H}(?)]$ & [ D...A(?) ] & $\mathrm{d}[\mathrm{H} . . . A(?)$ & ?[X-H...A $\left.\left(^{\circ}\right)\right]$ \\
\hline C10-H10A...Cl & $0.981(0)$ & $3.040(1)$ & $2.704(1)$ & $100.52(3)$ \\
\hline C6-H6...N1 $1^{(i)}$ & $0.885(0)$ & $3.568(2)$ & $2.865(1)$ & $137.55(3)$ \\
\hline \multicolumn{5}{|c|}{ Symmetry code: (i) $-x+2,-y,-z$} \\
\hline
\end{tabular}

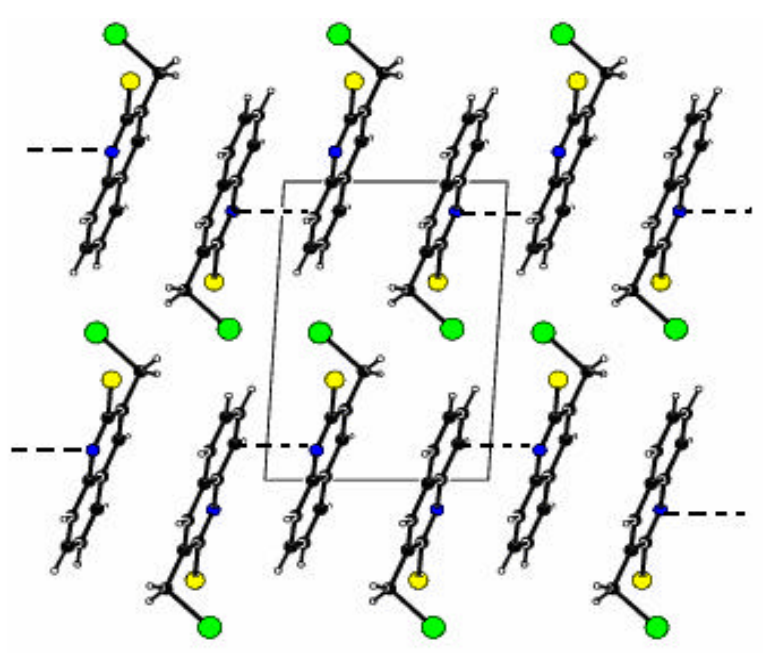

Fig. 3. Unit cell molecular packing along a-axis giving rise to C6-H6...N1 hydrogen bonded network.

Fig. 3 depicts the C6-H6...N1 intermolecular interaction involved in infinite hydrogen bonded molecular network. The geometry of both the hydrogen bonded interactions is presented in Table 6 .

\section{ACKNOWLEDGEMENTS}

The corresponding author (Rajnikant) is thankful to the Ministry of Science and Technology, Govt. of India, New Delhi for the financial support under its research no. SR/ S2/CMP-47/2003.

\section{REFERENCES}

Chand, B. (2008). A study of molecular and crystal structures of some steroidal molecules', Ph.D. Thesis University of Jammu, Jammu Tawi, India.

CrysAlis ${ }^{\text {Pro }}$ and CrysAlisRED (2007). Softwares for crystal data collection and reduction, Oxford Diffraction Limited, Abingdon, Oxfordshire, England.
Duax, W.L. and Norton, D.A. (1975). Atlas of Steroid Structure, New York, Plenum Press, 1, 18.

Farrugia, L. J. (1997), Molecular Graphics-ORTEP-3 for Windows. Journal of Applied Crystallography, 30, 565.

Garcia, M. S., Martinez, J. A. H., Palma, A.R. and Kpuznetsov, V. (2000). Crystal structure of Spiro[cyclohexane-1,2'-6'methoxy-1' -(a-chloroacetyl)-1',2',3',4'-tetrahydro-4' methyl quinoline. Analytical Sciences, 16: 889.

Gilchrist, T.L. (1997). Heterocyclic Chemistry', $3^{\text {rd }}$ ed., Addison Wesley Longman, England, 231.

Kouznetsov, V., Palma, A., Ewert, C. and Varlamov, A. (1998). Some aspects of reduced quinoline chemistry, Journal of Heterocyclic Chemistry, 35: 761.

Lekhok, K.C., Prajapati, D. and Boruah, R.C. (2008). Indium(III) Trifluoromethanesulfonate: An efficient reusable catalyst for the alkynylation- Cyclization of 2- Aminoaryl ketones and synthesis of 2, 4- disubstituted quinolines. Synlet, 5: 0655-0658.

Nardelli, M. (1995). A system of computer routines for calculating molecular structure parameters from the results of crystal structure analysis, Journal of Applied Crystallography, $28: 59$.

Palani, K., Ponnuswamy, A., Ponnuswamy, M.N.G., Yathirajan, H.S., Prabhuswamy, B., Raju, C.R., Nagaraja, P. and Shashikanth, S. (2004). Crystal structure of 2-chloro-3(ß-nitrovinyl)quinoline, Analytical Sciences, 20: 403.

Rajnikant, Gupta, V. K., Deshmukh, M. B., Varghese, B. and Dinesh (2002). Crystal structure analysis of 4phenylquinolin-2-(1H)-one. Crystallographic Reports, 47: 449.

Robert, A. and Meunier, B. (1998). Is alkylation the main mechanism of action of the antimalarial drug artemisinin, Chemical Society Review, 27: 273.

Saito, I., Sando, S., and Nakatani, K. (2001). Improved selectivity for the binding of napthyridine dimmer to quininequanine mismatch, Bioorganic and Medicinal Chemistry Letters, 9:2381.

Schneider, G., Baringhaus, K-H and Hugo (2008). In: Molecular 
design: Concepts and Applications, Wiley-VCH, 262

Sheldrick, G.M. (1986). SHELXS86: Program for crystal structure determination, University of Gottingen, Germany. Sheldrick, G.M. (1997). SHELXL97: Program for the refinement of crystal structures, University of Gottingen, Germany.

Sudha, L., Subramanian, K., Sivaraman, J., Ramakrishnan, V.T.R., Steiner, Th. and Koellner, G. (1995a). 5(Isopropylamino)- 8-methyl-2-quinoline. Acta Crystallography, C51: 1026.
Sudha, L., Subramanian, K., Sivaraman, J., Sriraghavana, K. and Steiner,Th. (1995b). 5- Amino- 8-methyl-2-quinoline. Acta Crystallography, C51: 1689.

Sudha, L., Subramanian, K., Steiner, Th., Koellner, G., Ramakrishnan, V.T.R. and Sriraghavana, K. (1997). 5Dimethylamino-8-methyl-2-quinoline. Acta Crystallography, C53: 606. 